\title{
Eksistensi Permainan Tradisional Sebagai Warisan Budaya Bangsa
}

\author{
Gustiana Mega Anggita ${ }^{a}$, Siti Baitul Mukarromah ${ }^{b}$, Mohammad Arif Ali $^{c}$ \\ a,b,c Universitas Negeri Semarang, Central Java 50229, Indonesia
}

"Corresponding author: mega.anggita@mail.unnes.ac.id, sitibaitul@mail.unnes.ac.id,

\section{ART ICLE INFO}

Article history:

Received 18 October 2018

Received in revised form 18

October 2018

Accepted 14 November 2018

Keywords:

existence, tradisional games, nation's cultural heritage

\begin{abstract}
A B S T R A C T
Objective: to determine the existence, amount and types of traditional games which are in the district of Semarang. Methods: This study was descriptive qualitative research with survey method. Samples from this study is the physical education teacher and elementary school students who are in the district of Semarang. Data collection techniques in this study using questionnaires, interviews and documentation. Results: The results of the study show the following: (1) There are various traditional games in Semarang District; (2) the number of traditional games contained in Semarang District of ten traditional game consists of: Bentengan, Gobak Sodor, Sunda Manda, Bakiak, Bintang Bergilir, Bola Bakar, Egrang, Rok Dodok, Kucing Tikus dan Ular Naga; (3) traditional games which are in the district of Semarang who often played the children of eight games consist of: Bentengan, Gobak Sodor, Sunda Manda, Kucing Tikus, Bintang Bergilir dan Bola Bakar. Conclusion: The traditional game contained in Semarang district as many as ten games and traditional games are often played in Semarang district as many as six games.
\end{abstract}

\section{Pendahuluan}

Permainan dan bermain merupakan bagian dari dunia anak-anak. Melalui bermain permainan anak-anak dapat memperoleh kesenangan. Bermain permainan merupakan salahsatu jenis aktivitas fisik yang dapat membantu tumbuh kembang anak. Namun, seiring dengan kemajuan ilmu pengetahuan dan teknologi (IPTEK), bermain tidak lagi menjadi aktivitas fisik yang mendukung tumbuh kembang anak. Permainan yang dimainkan adalah jenis permainan sepeti game online atau permainan yang terdapat pada gadget. Subrahmayan (Ukasyah dan Irfansyah, 2015: 125) menyatakan anak cenderung tidak bergerak ketika memainkan permainan yang sudah memanfaatkan teknologi. Anak hanya duduk di depan televisi dan bermain dengan menggunakan media tanpa banyak bergerak. Hal ini pada akhirnya mengakibatkan anak memiliki kecenderungan untuk mengalami obesitas. Tidak hanya berdampak pada pertumbuhan dan perkembangan fisik anak tetapi juga berdampak pada perkembangan sosial, emosional dan mental anak. Lanjut Rusli
Lutan (2001: 17) menyatakan perkembangan jasmani anak tidak semata-mata bergantung pada proses kematangan. Perkembangan itu juga dipengaruhi oleh pengalaman gerak anak baik ditinjau dari aspek mutu maupun banyaknya pengalaman itu. Anak harus memperoleh kesempatan yang banyak untuk bergerak dan bermain. Oleh karena itu, seiring dengan adanya kemajuan IPTEK tersebut tidak semata-mata diterima tetapi hatus ada pengendalian guna meminimalisir dampak negatif yang terjadi dalam kehidupan khususnya bagi generasi penerus bangsa atau anak-anak.

Pada dasarnya anak-anak membutuhkan aktivitas fisik yang memadai untuk merangsang pertumbuhan dan perkembangan anak. Aktivitas fisik yang dilakukan juga akan bermanfaat bagi kesehatan dan kebugaran tubuh anak. Salah satu aktivitas fisik yang sering dilakukan anak-anak adalah bermain suatu permainan. Dengan bermain banyak manfaat yang dapat diperoleh anak misalnya, anak menjadi senang, dapat menjalin persahabatan, memperkaya gerak yang dimiliki anak dan dapat belajar keterampilan baru. Permainan tradisional merupakan salah satu sarana bermain bagi anak. Selain bermanfaat bagi 
kesehatan, kebugaran dan tumbuh kembang anak, terdapat juga nilai-nilai positif yang terkandung dalam permainan tradisional misalnya kejujuran, kerjasama, sportif, tolong menolong, tanggung jawab, disiplin dan masih banyak lagi dimana hal-hal tersebut dapat membangun karakter anak. Selain itu, Permainan tradisional merupakan salah satu sarana bermain bagi anak. Selain bermanfaat bagi kesehatan, kebugaran dan tumbuh kembang anak, terdapat juga nilai-nilai positif yang terkandung dalam permainan tradisional misalnya kejujuran, kerjasama, sportif, tolong menolong, tanggung jawab, disiplin dan masih banyak lagi dimana hal-hal tersebut dapat membangun karakter anak. Selain itu, Permainan tradisional lebih efektif dari kegiatan sehari-hari dalam rangka untuk mengembangkan kontrol objek, kemampuan lokomotor dan keterampilan dasar (Hakimeh Albari dkk, 2009: 126). Permainan tradisional yang terstruktur sedemikian rupa secara langsung mempengaruhi psikomotor, perkembangan kognitif dan emosional anak. Permainan tradisional dapat mempengaruhi peningkatan kesenangan dari pemain dan positif mempengaruhi perkembangan anak secara keseluruhan (Tatjana Kovačević and Siniša Opić, 2014: 100).

Sebagian besar permainan tradisional dan olahraga merupakan ekspresi budaya asli dan cara hidup yang memberikan kontribusi terhadap identitas umum kemanusiaan telang menghilang dan yang masih bertahan juga terancam hilang atau punah karena pengaruh globalisasi dan harmonisasi keragaman warisan olahraga dunia (Jogen Boro dkk, 2015: 88). Sekarang ini permainan tradisional sudah mulai ditinggalkan oleh anak-anak bahkan tidak sedikit anak-anak yang tidak tahu apa itu permainan tradisional. Anakanak hanya melakukan aktivitas fisik di sekolah sebagai bagian dari proses pendidikan. William Tedi (2015: 8) menyatakan bahwa hilangnya permainan tradisional disebabkan oleh beberapa faktor yaitu: (a) sarana dan tempat bermain tidak ada, (b) adanya penyempitan waktu, terlebih lagi semakin kompleknya tuntutan zaman terhadap anak yang semakin membebani, (c) permainan tradisional terdesak oleh permainan modern dari luar negeri dimana tidak memakan tempat, tak terkendala waktu baik itu siang hari, pagi, sore ataupun malam bisa dilakukan serta tidak perlu menunggun orang lain untuk bermain, (d) terputusnya pewarisan budaya yang dilakukan oleh generasi sebelumnya dimana mereka tidak sempat mencatat, mendata dan mensosialisasikan sebagai produk budaya masyarakat kepada generasi dibawahnya. Tatjana Kovačević and Siniša Opić (2014: 109) menyatakan bahwa permainan tradisional jarang dimainkan pada jam istirahat sekolah dan class meeting, hal tersebut terjadi karena beberapa hambatan yang berhubungan dengan kurangnya ruang dan waktu untuk bermain di sekolah karena jumlah jumlah siswa di kelas yang banyak dan sedikitnya ruang untuk bermain. Solehudin (Jose Jjoossee, 2012) menyatakan bermain merupakan suatu kegiatan yang memakai alat atau tidak memakai alat secara spontan, fleksibel, menyenangkan, tidak terpaksa dan mengembangkan daya imajinasi anak, tanpa mempertimbangkan hasil akhir. Dengan demikian bermain dapat diartikan sebagai suatu aktivitas yang dilakukan baik memakai alat atau tidak memakai alat yang bersifat menyenangkan dan membantu pertumbuhan dan perkembangan anak. Menurut Rochjadi Hasan (Jose Jjoossee, 2012) bahwa dunia anak adalah dunia bermain, dimana bermain bagi mereka dapat dikatakan Core Actifity atau atau aktifitas utama. Slamet Suyanto (2005: 119-121) menyatakan bermain memiliki peranan penting dalam perkembangan anak pada hampir semua bidang perkembangan, baik perkembangan fisik-motorik, bahasa, intelektual, moral, sosial, maupun emosional.

Pada dasarnya permainan tradisional merupakan warisan budaya bangsa dan warisan dari nenek moyang yang keberadaannya harus dilestarikan. Sebagai anak bangsa sudah menjadi kewajiban untuk mempertahankan eksistensi dari permainan tradisional tersebut. Permainan tradisional bukan semata-mata permainan saja, akan tetapi terdapat nilai dan unsur budaya yang melekat didalamnya. Di seluruh penjuru Indoesia, setiap daerah memiliki permainan tradisional yang menjadi ciri khas dari daerah tersebut. Oleh karena itu, sosialisasi permainan tradisional harus sering dilakukan secara berkelanjutan. Dengan kata lain harus ada konservasi terhadap permainan tradisional itu sendiri. Hal tersebut dilakukan untuk mengatisipasi hilangnya atau punahnya permainan tradisional yang ada di Indonesia.

Berdasarkan uraian di atas, peneliti bermaksud melakukan identifikasi permainan tradisional yang terdapat di Indonesia khususnya di Kabupaten Semarang.

\section{Metode Penelitian}

Penelitian ini merupakan penelitian deskriptif kualitatif dengan pendekatan survey. Menurut Sugiyono (2007: 1) metode 
penelitian kualitatif adalah Metode penelitian yang digunakan untuk meneliti pada kondisi obyek yang alamiah, (sebagai lawannya adalah eksperimen) dimana peneliti adalah sebagai instrumen kunci, teknik pengumpulan data dilakukan secara triangulasi (gabungan), analisis data bersifat induktif, dan hasil penelitian kualitatif lebih menekankan makna dari pada generalisasi. Subyek penelitian dalam penelitian ini adalah Guru Sekolah Dasar (SD) yang terdapat di Kabupaten Semarang.

Teknik pengumpulan data dalam penelitian ini adalah wawancara, kuisioner, observasi dan dokumentasi. Instrumen pengumpulan data dalam penelitian ini disusun oleh peneliti sendiri yang berupa rubrik wawancara, rubrik observasi dan angket. Dalam penelitian ini terdapat dua jenis data yang digunakan yaitu data primer dan data sekunder. Data primer dalam penelitian ini terdiri dari rubrik wawancara dan rubrik angket. Sedangkan data sekunder yang akan digunakan sebagai pendukung dalam penelitian ini adalah observasi dan dokumentasi. Teknik analisis data menggunakan reduksi data, penyajian data dan penarikan kesimpulan.

\section{Hasil}

Berdasarkan data yang diperoleh jenis permainan tradisional yang terdapat di Kota dan Kabupaten Semarang terdapat pada gambar 1.

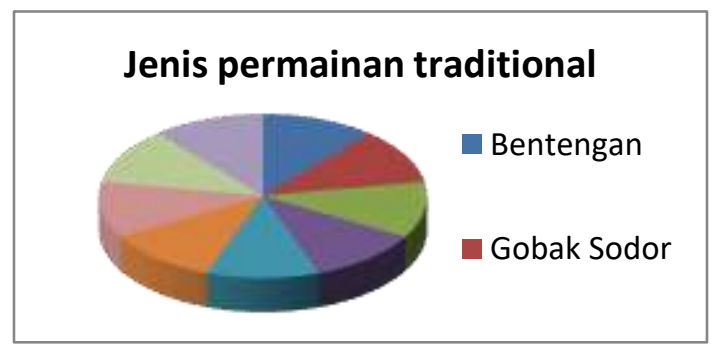

Gambar 1. Jenis Permainan Tradisional di Kabupaten Semarang

Berdasalkan data yang diperoleh jenis permainan tradisional yang paling sering dimainkan oleh anak-anak di Kabupaten Semarang terdapat pada gambar 2 .

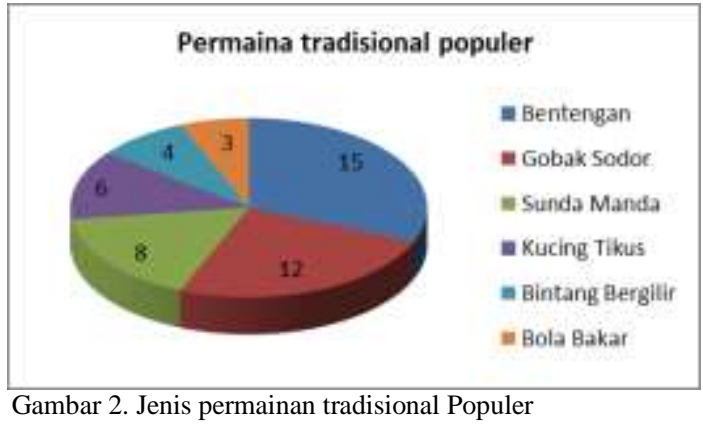

Bermain dan permainan sangat identik dengan anak-anak. Bermain juga merupakan salah satu kegiatan jasmani yang sering dilakukan anakanak. Melalui bermain ini anak memperoleh pengalaman gerak yang bermanfaat bagi pertumbuhan dan perkembangan anak. Permainan tradisional berkembang dari kebiasaan masyarakat tertentu yang kemudian menjadi bentuk kegiatan permainan dan olahraga. Pada perkembangan selanjutnya permainan tradisional dijadikan sebagai jenis permainan yang memiliki ciri kedaerahan asli yang disesuaikan dengan budaya daerah setempat. Permainan tradisional ini yang sering dimainkan anak-anak mulai dari lingkungan sekitar rumah sampai lingkungan sekolah. Dengan demikian permainan tradisional sangat penting dijaga dan dilestarikan keberadaannya mengingat pentingnya manfaat dari permainan tradisional itu sendiri dan nilainilai budaya yang terdapat didalamnya.

Berdasarkan data yang diperoleh dari penelitian ini, permainan tradisional yang terdapat di Kabupaten Semarang masih sering digunakan sebagai media dalam proses pembelajaran penjas di sekolah khususnya di sekolah dasar. Selain itu, dari data kuisioner dan wawancara yang dilakukan pada guru dapat diketahui bahwa keberadaan permainan tradisional yang ada di Kabupaten Semarang tidak terlepas dari peran guru penjas yang hampir pada setiap pembelajaran penjas selalu mensisipkan permainan tradisional. Para guru menjadikan kegiatan pembelajaran sebagai sarana untuk mengenalkan dan melestarikan permainan tradisional yang terdapat di Kabupaten Semarang. Oleh karena itu peran guru penjas sangat penting dalam memfasilitasi anak-anak untuk mengenal permainan tradisional dan berpartisipasi aktif didalamnya guna melestarikan warisan budaya bangsa tersebut.

Permainan tradisional yang terdapat di Kabupaten Semarang jumlahnya cukup beragam yaitu ada sepuluh jenis permainan tradisional yang terdiri dari Bentengan, Gobak Sodor, Sunda Manda, Bakiak, Bintang Bergilir, Bola Bakar, Egrang, Rok Dodok, Kucing Tikus dan Ular Naga. Namun, permainan tradisional yang paling sering 
dimainkan yaitu Bentengan, Gobak Sodor, Sunda

Manda, Kucing Tikus, Bintang Bergilir dan Bola Bakar. Dapat dikatakan bahwa keberadaan permainan tradisional di Kabupaten Semarang masih cukup baik walaupun sebagian besar permainan lebih sering dilakukan ketika jam pelajaran penjas di sekolah dan tidak jarang juga dimainkan ketika jam istirahat di sekolah. Walaupun keberadaan permainan tradisional dirasakan masih cukup baik, namun responden dalam penelitian ini mengungkapkan bahwa popularitas dari permainan tradisional tersebut mengalami penurunan seiring dengan perkembangan zaman yang semakin modern. Dengan adanya perkembangan ilmu pengetahuan dan teknologi, bermain dan memainkan permainan bisa dilakukan dimana saja tanpa harus menyiapkan alat, sarana dan prasarana, permainan tersebut dapat dimainkan dengan komputer, laptop bahkan dapat dimainkan dengan handphone.

Dengan demikian dapat dikatakan keberadaan permainan tradisional di Kabupaten Semarang masih cukup baik. Hal tersebut dapat terlihat dari jumlah dan jenis permainan tradisional yang dimainkan anak-anak yang beragam. Jumlah permainan tradisional yang terdapat di Kabupaten Semarang yaitu sepuluh jenis permainan dan permainan tradisional yang sering dimainkan oleh anak-anak di Kabupaten Semarang terdiri dari Bentengan, Gobak Sodor, Sunda Manda, Kucing Tikus, Bintang Bergilir dan Bola Bakar. Perkembangan permainan tradisional di Kabupaten Semarang tidak terlepas dari peran serta guru penjas dalam mengenalkan dan menggunakan permainan tradisional sebagai media pembelajaran penjas di sekolah.

\section{Simpulan dan Rekomendasi}

\section{Simpulan}

Berdasarkan hasil penelitian dapat ditarik kesimpulan sebagai berikut: (1) keberadaan atau eksistensi permainan tradisional yang terdapat di Kabupaten Semarang cukup baik, (2) jumlah permai nan tradisional yang terdapat di Kabupaten Semarang yaitu sepuluh jenis permainan yang terdiri dari: Bentengan, Gobak Sodor, Sunda Manda, Bakiak, Bintang Bergilir, Bola Bakar, Egrang, Rok Dodok, Kucing Tikus dan Ular Naga, (3) jenis permainan tradisional yang sering dimainkan anak-anak di Kabupaten Semarang cukup beragam yang terdiri dari: Bentengan, Gobak Sodor, Sunda Manda, Kucing Tikus, Bintang Bergilir dan Bola Bakar.

\section{Rekomendasi}

Berdasarkan hasil penelitian yang telah dilakukan, diketahui bahwa keberadaan permainan tradisiona di Kabupaten Semarang dapat dikatakan masih cukup baik. Jumlah dan ragam permainan tradisional yang terdapat di Kabupaten Semarang cukup banyak. Walaupun demikian, berdasarkan hasil penelitian yang telah dilakukan popularitas permainan tradisional di Kabupaten Semarang mengalami penurunan dari masa sebelumnya. Oleh karena itu, perlu adanya perhatian khusus pada permainan tradisional dari berbagai pihak guna mempertahankan keberadaan dan keberlangsungan permainan tradisional yang ada di Indonesia khususnya di Kabupaten Semarang.

Permainan tradisional merupakan salah satu warisan budaya bangsa Indonesia dimana pada setiap permainan tradisional terdapat ciri khas dan nilai kearifan lokal dari setiap daerah yang terdapat di Indonesia. Selain itu, permainan tradisional merupakan sarana bagi anak untuk memperoleh pengalaman gerak yang berguna bagi pertumbuhan dan perkembangan fisik anak. Oleh karena itu perlu adanya sosialisasi dan pelestarian permainan tradisional secara berkelanjutan.

\section{Daftar Pustaka}

Conny R, Semiawan. (2002). Belajar dan pembelajaran dalam taraf usia dini. Indonesia: PT Ikrar Mandiri Abadi.

Jose Jjoossee. (2012). Bermain sambil belajar. Diambil pada tanggal 18 Juni 2016 dari http://bermainsambilbelaja.blogspot.com/.

Moniqa Siagawati, dkk. 2007. Indigenous, Jurnal Ilmiah Berkala Psikologi volume 9, No.1, Mei 2007: 83-95.

Slamet Suyanto. (2005). Dasar-dasar pendidikan anak usia dini. Yogyakarta: Hikayat Publishing.

Sugiyono. 2007. Metode penelitian kuantitatif kualitatif dan $R \& D$. Bandung: Alfabeta.

Syaiful Hasan, dkk. Jurnal Pendidikan Olahraga, Volume 4, No. 2, Desember 2015.

Haerani Nur. Jurnal Pendidikan Karakter tahun III No. 1, Februari 2013: 87-9. Membangun Karakter Anak Melalui Permainan Anak Tradisional. Makassar. 
Ukasyah Q.A.P dan Irfansyah. Jurnal Sosioteknologi Volume 14 No. 2, Agustus 2015: 124-140. Identifikasi Faktor-Faktor Permainan Tradisional Bebentengan sebagai Basis Perancangan Game Pemicu Peningkatan Sistem Motorik Anak. Bandung.

Tuti Andriani. Jurnal Sosial Budaya Volume 9 NO. 1, Januari-Juli 2012: 121-136. Permainan Tradisional dalam Membentuk Karakter Anak Usia Dini. Riau.

William Tedi. Sociologique Volume 3 NO. 4, Desember 2015: 1-17. Perubahan Jenis Permainan Tradisional menjadi permainan Modern Anak-Anak Di Desa Ijuk Kecamatan Belitang Hulu Kabupaten Sekadu. Pontianak

Hakimeh Akbar et al. Iranian Journal of Pediatrics Volume 19 No. 2, Juni 2009: 123-129. The Effect of Traditional Games in Fundamental Motor Skill Development in 7-9 Years Old Boys. Iran.

Tatjana Kovačević and Siniša Opić. Croatian Journal of Education Volume 16 No. , 2014: 95-112. Contribution of Traditional Games to The Quality of Student Relatian and Frequency of Student Socialization in Primary Education. Kroasia.

Jogen Boro et al. IOSR Journal of Humanities and Social Science (IOSR-JHSS) sVolume 20 Issue 3 Ver. V1, March 2015: 87-91. 